\title{
SOCIOGRAFÍA ELEMENTAL DEL CAMPO RELIGIOSO PROTESTANTE EN MUNICIPIOS DE LA FRONTERA NORTE Y TABASCO*
}

\author{
Por \\ José Luis Molina Hernández ${ }^{* *}$
}

\begin{abstract}
RESUMEN
La transformación del campo religioso mexicano es un hecho claro, manifestado en la disminución del porcentaje de feligreses católicos con respecto a los de otras afiliaciones religiosas, así como la proliferación de grupos distintos. Pese a ello, es poco lo que sabemos con respecto a la naturaleza y dirección de esa transformación, aun en aquellas regiones del campo religioso en las cuales ha alcanzado niveles sin precedente. El presente trabajo pretende contribuir al conocimiento de esas transformaciones mediante el análisis de la composición y evolución de segmentos específicos del camporeligioso, parte ambos de las zonas de cambio acelerado, como los son los municipios de la frontera norte y de Tabasco. Mediante el uso de diversas técnicas de análisis, se construye un perfil regional y municipal que sirve como muestra de lo que pasa en el campo religioso general, y que nos permite tener una idea de qué grupos crecen, en dónde, con qué ritmos y a qué causas podemos atribuirle dicho crecimiento. El análisis comparativo revela, además, las profundas diferencias existentes en ambas regiones en cuanto al tipo de grupos que están creciendo, sus etapas de dicho crecimiento, y la naturaleza más o menos plural de cada municipio y región.
\end{abstract}

\begin{abstract}
The transformation of the Mexican religious field is a clear reality, minifested by the decreased amount of catholic feligreses in relation to the affiliated religions, also the proliferation of different groups. Nevertheless, it is little wath we know in relation to the nature and direction of this transformation, even in those regions where the religious field has reached unprecedented levels. This research tends to contribute to the knowledge of those transformations by the analysis of the composition and evolution or the specific segments of the religious field, from both zones of the accelerated change, like that of the counties of the northern frontier and of Tabasco. By the use of diverse analysis techniques, a desired region and county model is constructed that serves as an example of what occurs in the general religious field, and that permits us to have an idea of what groups grow, where, with what rhythm and what causes can we attribute to the growth. The comparative analysis reveals, also, the profound existing differences in both regions referring to the type of groups that are growing, their growth stages, and the plural nature more or less of each county and region.
\end{abstract}

* Este trabajo forma parte del proyecto "Los hijos de los testigos de Jehová en las escuelas públicas de educación básica en Baja California", tesis doctoral en curso del mismo autor, dentro del doctorado del Ciencias Sociales de El Colegio de la Frontera Norte.

** Profesor-investigador de la Universidad Pedagógica Nacional, unidad Mexicali; sociólogo; maestro en desarrollo urbano y candidato a doctor en ciencias sociales por El Colef. 


\section{INTRODUCCIÓN}

El conocimiento preciso de la composición del campo religioso ${ }^{1}$ mexicano, estálejos de ser una mera curiosidad científica. Los diferentes grupos se distinguen no sólo en lo que toca a sus características religiosas, es decir, a sus doctrinas, ritos y formas de organización, sino también en una amplia gama de prácticas sociales (Valderrey, 1983).

Aspectos de la vida social como los valores cívicos, el destino escolar de muchos niños, el uso de espacios públicos para actividades religiosas, las formas de control sobre los miembros, la posición con respecto a procesos políticos, entre otras, son muestra de cómo la adscripción religiosa es un hecho que trasciende el campo religioso para constituirse en una parte fundamental de la vida cotidiana.

La ideología religiosa de cada grupo implica una visión particular de la realidad, un recorte cuyos límites son determinados en parte (dependiendo del nivel de involucramiento individual), por la tradición religiosa, por la orientación específica del grupo dirigente, y por el carácter práctico que representa adherirse a verdades relativamente incuestionables.

A verdades religiosas múltiples y en competencia, corresponden distintos modelos de comportamiento social, diseñados y promovidos con mayor o menor éxito desde los núcleos de poder sociorreligioso de cada grupo. En este sentido, el crecimiento de grupos como los davidianos o los moonies, tiene implicaciones sociales muy diferentes a la expansión de la Iglesia Apostólica de la $\mathrm{Fe}$ o de los adventistas, y lo mismo sucede en el caso de los luteranos, de la Luz del Mundo, de los bautistas o de los mormones.

Por otra parte, el desarrollo de éstos no es ajeno a las leyes del mercado: ${ }^{2}$ hay una oferta y una demanda de bienes simbólicos de salvación; se observan tendencias monopólicas, oligopólicas y de competencia perfecta; existe la inclinación hacia la estandarización de los productos (la figura del pastor, entre ellas); hay una determinada distribución del mercado entre las fuerzas competidoras; con el dominio claro de unas

Pierre Bourdieu (1971) entiende el campo religioso como un espacio teórico donde: i) Se puede reconstruir la lógica de la interacción entre: agentes e instituciones productores y distribuidores de los bienes simbólicos de salvación, y los sectores sociales que adquieren tales bienes de acuerdo con el juego de la oferta y la demanda. ii) Los agentes e instituciones productores entran en competencia para detentar el capital religioso y el poder religioso en un campo religioso históricamente determinado (cfr. Bastián, 1986).

${ }^{2}$ En tanto mercado de bienes simbólicos de salvación, el campo religioso posee una demanda determinada por las condiciones generales de existencia (económicas, políticas, culturales, religiosas), y una oferta que depende de la composición y dinámica internas del campo religioso (Hill, 1976). 
pocas organizaciones, en la base encontramos una gran volatilidad en la aparición y desaparición de pequeñas sectas, justo como sucede con las microempresas, etcétera.

El mercado de bienes simbólicos de salvación está contenido en un campo de fuerzas mayor, que trasciende a los grupos individualmente considerados, y en este marco más general es donde se definen las relaciones con los grupos e instituciones sociales seculares; es decir, aquí se localizan sus conexiones con el mundo de la política, de la cultura institucionalizada, de la educación y mucho más. Desde esta optica, el análisis del campo religioso nos aproxima, a la vez, al mundo de los valores sociales y culturales de la población, siempre tan difícil de representar.

En términos cuantitativos, estamos hablando de más de 4000000 de protestantes a nivel nacional, y cerca de 200000 en el conjunto de municipios que someteremos a análisis en este trabajo.

Esta distribución del mercado tiene además una expresión espacial, geográfica, que permite su representación física; cuando se analiza la distribución de la feligresía de las denominaciones sobre el territorio, generalmente no se encuentran comportamientos erráticos sino, por el contrario, patrones de adscripción religiosa claramente definidos en cada región del campo (Molina, 1996). Es necesario, por tanto, ir más allá de los niveles de agregación demasiado genéricos, como los de la nación o de las categorías censales, y ver bajo el microscopio las regiones y microrregiones del campo religioso nacional.

\section{PROCEDIMIENTO ANALÍTICO}

Así pues, dada la importancia social, teórica y estadística que tiene el conocimiento puntual de las pautas de comportamiento religioso que se desarrollan en la sociedad mexicana, y que la afectan en su conjunto, nos proponemos contribuir con este ejercicio, modesto en sus alcances y cobertura, a la construcción de esa necesaria sociografía del territorio religioso nacional.

Para entender el lugar que ocupan las distintas denominaciones dentro de él, es necesario responder a diversas interrogantes, como las siguientes: ¿es diferente su desarrollo según las diferentes regiones?, ¿cuáles son las principales fuerzas religiosas en cada entidad y cómo se distribuyen el campo?, ¿cómo podemos explicar su desarrollo ahí y no en otras partes?, ¿cómo varía el desarrollo de los distintos grupos a lo largo del tiempo?, ¿qué relación tienen con variables tales como el tamaño de las ciudades o el sustrato cultural y religioso?, ¿hay diferencias significativas en el grado de participación entre las diferentes denominaciones? 
Esta pequeña muestra del conjunto de interrogantes sin respuesta que enfrentamos en la actualidad, por su carácter elemental pone en evidencia las serias limitaciones de nuestro conocimiento del campo religioso, en particular en lo que a información sociográfica se refiere. Los grandes esfuerzos emprendidos a finales de la década pasada, ${ }^{3}$ quedaron truncos o no han tenido continuidad, por lo cual carecemos de sociografías nacionales y aun regionales que den sustento a una visión más precisa.

En concordancia con lo anterior, el objetivo central de este trabajo es establecer el perfil sociográfico del campo religioso en los segmentos específicos para los cuales disponemos de datos confiables. Por tratarse de tres municipios de Baja California, uno de Chihuahua y siete de Tabasco, el análisis nos presenta dos subregiones de los dos grandes polos de transformación del campo religioso nacional: los estados del sureste y los de la frontera norte, regiones fronterizas ambas, lejanas del centro histórico de poder político y religioso.

Tras establecer algunos rasgos generales de los municipios estudiados, y del campo religioso global en que se ubican las dos subregiones, iniciaremos el análisis determinando la composición actual y la evolución a lo largo del siglo de los dos conjuntos, tanto a nivel de municipios como de denominaciones; luego estudiaremos con cierto detalle la composición y evolución específica de cada municipio y de las principales denominaciones. En seguida, mediante la construcción de un índice ex profeso, indagaremos en sus tendencias a la diversificación (distribución del campo entre varias organizaciones, más de dos por lo regular) y/o a la especialización (concentración en uno o pocos grupos). Y finalmente, concluiremos con un análisis comparativo de los grados de participación que se registran en las diferentes denominaciones, y en cada uno de los dos subcampos, a fin de ver qué relación guardan con la evolución de cada grupo.

La escasez de bases de datos confiables —es decir, obtenidos con procedimientos rigurosos en su metodología - nos obliga a recurrir a los pocos instrumentos disponibles; no obstante, los que fueron seleccionados para su procesamiento, tienen la suficiente pulcritud metodológica como para permitirnos tener una visión general del campo. En este caso nos apoyaremos en diferentes encuestas sociológicas levantadas entre 1987 y 1990: una es el Inventario de organizaciones religiosas, de El Colef, de la que tomamos los datos correspondientes a Ciudad Juárez y Tijuana en 1987 (complementado con datos tomados directamente de los trabajos de

3 Como el inconcluso Proyecto Fronteras (1988), de José Valderrey, y el inventario levantado por el Colef (1987), que junto con otros esfuerzos más localizados prometían darnos luz sobre el perfil religioso actual del país. 
Alberto Hernández, 1988 y 1996); otra es la que levantó José Valderrey en siete municipios de Tabasco, en 1988 (Valderrey, 1988); ${ }^{4}$ una más corresponde al caso de Mexicali, trabajado por Molina, Gutiérrez y Vásquez Malo en 1988 (Molina, et. al., 1989); y la cuarta es la levantada en Tecate por Molina en 1990 (Molina, 1993).

Con estos datos, y el complemento de otras fuentes en algunos momentos específicos, trataremos de establecer el perfil religioso de cada segmento del campo. Para ello, apelaremos a diversos procedimientos analíticos, tales como series de tiempo, tablas de contingencia, correlaciones y construcción de índices, y al apoyo de abundante material gráfico ${ }^{5}$ como soporte visual.

A través de estos ejercicios mínimos, nos acercaremos a un nivel analítico particular de las denominaciones, desde el cual se ven como fuerzas competidoras en mercados religiosos de alta concurrencia. Cabe recordar que de acuerdo con el Censo de población y vivienda de 1990, Tabasco ocupa el segundo lugar en población no católica, en medio de la zona de mayor transformación del campo religioso, y Baja California y Chihuahua son parte de la otra gran región de retroceso del catolicismo.

\section{COMPOSICIÓN Y EVOLUCIÓN GENERAL}

Una primera mirada armada con fuentes diversas, nos permite aproximarnos a la composición de los subcampos según corrientes principales. ${ }^{6}$ Las figuras 1 y 2 muestran los casos de ocho municipios de la frontera norte (incluyendo los cuatro que tenía en ese momento Baja California), en los que se pueden ver el predominio claro del pentecostalismo en todos ellos, dando lugar a siete campos homogéneos, ${ }^{7}$ y uno (el de Tecate) bifurcado, casi homogéneo ( $42 \%$ pentecostal). La figura 3 muestra la composición de los cinco estados del sureste, con iguales resultados, si consideramos que las iglesias presbiterianas se pentecostalizaron en la región desde la

\footnotetext{
A ambos se les agradece su generosidad al facilitarnos las bases de datos correspondientes.

De hecho, ya que se trata de describir la composición de los campos, las gráficas juegan un papel fundamental, toda vez que permiten visualizar de golpe la distribución del campo entre las denominaciones, y en ese sentido facilitan el análisis.

A diferencia de las denominaciones, que son por lo regular organizaciones individuales, las corrientes comprenden un conjunto más o menos amplio de denominaciones y congregaciones independientes que observan una práctica religiosa común, como, por ejemplo, el pentecostalismo.

De acuerdo con la tipología de Meneses (1977), un campo homogéneo es aquél en el cual una organización agrupa por sí sola 50\% o más de la feligresía del campo o segmento del campo del que se trate; un campo bifurcado es aquél en el cual dos organizaciones comprenden $50 \%$ o más; y un campo plural ista es el que tiene tres o más organizaciones como predominantes.
} 
década pasada; aunque la fuente de información de Giménez dista de ser la más confiable, ${ }^{8}$ el predominio pentecostal es tan grande que aun en estadísticas incompletas es notoria su hegemonía. Pero precisamente su escasa confiabilidad desautorizan mayores interpretaciones.

Podemos ya centrar el análisis, por lo tanto, en los municipios cubiertos por las encuestas ya mencionadas. El cuadro 1 presenta algunas características básicas en los municipios estudiados. Es notorio cómo, salvo el caso de Tecate, los municipios de la frontera norte son de mucho mayor volumen que los tabasqueños en cuanto a la población total, pero están casi en el mismo rango en cuanto a población protestante, lo que habla de una gran presencia de ésta en la sociedad tabasqueña, con porcentajes que se aproximan al 20\% (el porcentaje estatal para 1990 fue de $15 \%$ ), en tanto que entre los del norte sólo Tecate rebasa el 6\%, mientras que el promedio del los otros tres es de 5\%, y el promedio general para los municipios de la frontera norte es de $6.36 \%$ (Hernández, 1996).

También es claro cómo en todos los casos, la dinámica de crecimiento del protestantismo es muy superior a la de la población en general, aunque estos incrementos porcentuales varían considerablemente al interior de las propias regiones.

\section{CUADRO 1. Población total y población protestante en municipios seleccionados de la frontera norte y Tabasco, 1980-1990.}

\begin{tabular}{|c|c|c|c|c|c|c|c|c|c|}
\hline & \multicolumn{3}{|c|}{ Población 1980} & \multicolumn{3}{|c|}{ Población 1990} & \multirow{2}{*}{$\begin{array}{l}\text { Variación } \\
\text { porcentual }\end{array}$} & \multirow{2}{*}{$\begin{array}{l}\text { Miembros } \\
\text { (encuesta) }\end{array}$} & \multirow{2}{*}{$\begin{array}{l}\text { Cobert } \\
\text { de la en }\end{array}$} \\
\hline & Total & Protestan & e $\%$ & Total & Protestante & $\%$ & & & \\
\hline Ciudad Juárez & 567365 & 26394 & 4.7 & 680028 & 40028 & 5.9 & 1.2 & 20853 & 52.1 \\
\hline Mexicali & 510664 & 17885 & 3.5 & 518648 & 22254 & 4.3 & 0.8 & 25978 & 116.7 \\
\hline Tecate & 30540 & 2102 & 6.9 & 44449 & 4059 & 9.1 & 2.2 & 3510 & 86.5 \\
\hline Tijuana & 461257 & 19539 & 4.2 & 639451 & 31653 & 5.0 & 0.7 & 23855 & 75.4 \\
\hline Balancán & 37099 & 4814 & 13.0 & 41821 & 6613 & 15.8 & 2.8 & 3032 & 45.8 \\
\hline Cárdenas & 119325 & 21766 & 18.2 & 145943 & 28841 & 19.8 & 1.5 & 11925 & 41.3 \\
\hline Comalcalco & 101448 & 16524 & 16.3 & 120319 & 22479 & 18.7 & 2.4 & 9242 & 41.1 \\
\hline Emiliano Zapata & 17147 & 487 & 2.8 & 17174 & 1077 & 6.3 & 3.4 & 445 & 41.3 \\
\hline Huimanguillo & 94240 & 14992 & 15.9 & 112933 & 21989 & 19.5 & 3.6 & 2132 & 9.7 \\
\hline Paraíso & 41252 & 6211 & 15.1 & 50500 & 8069 & 16.0 & 0.9 & 3579 & 44.4 \\
\hline Tenosique & 38299 & 3836 & 10.0 & 40707 & 5292 & 13.0 & 3.0 & 1989 & 37.6 \\
\hline
\end{tabular}

FUENTE: Censos nacionales de población y vivienda, 1980 y 1990.

8 En los registros del gobierno hay una subnumeración de los grupos religiosos, ya que no todos se registran, y esta subnumeración era aún mayor antes de la reforma constitucional en materia religiosa, ya que muchos grupos, los Testigos de Jehová entre ellos, recelaban, y más del $50 \%$ no se registraban ante SEDUE. 


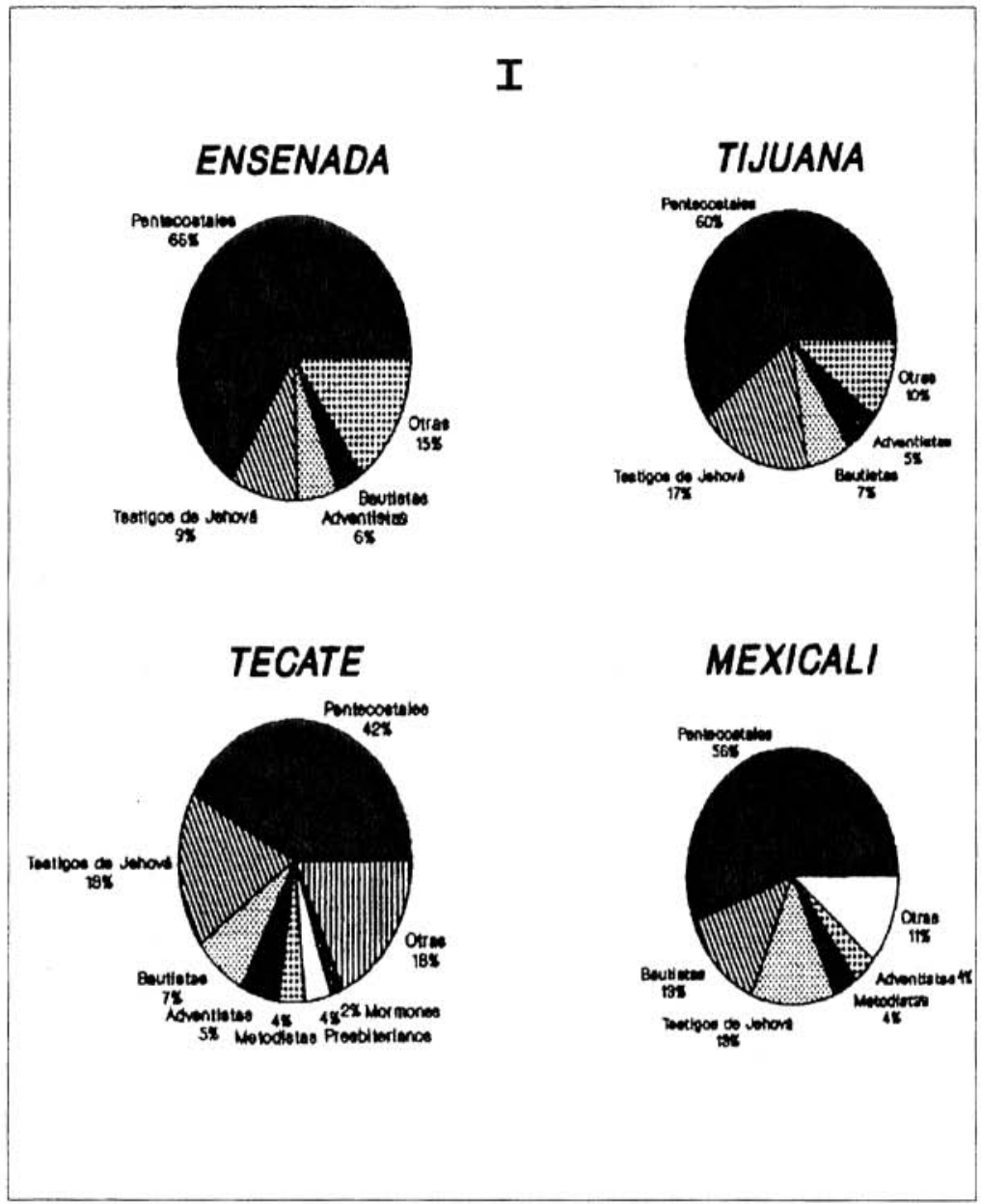

Figura 1. Campo protestante de la frontera norte por entidad según corrientes principales, 1988.

FUENTE: Alberto Hernández (1988); Eduardo Backhoff (1989); José Luis Molina (1988). 


\section{II}
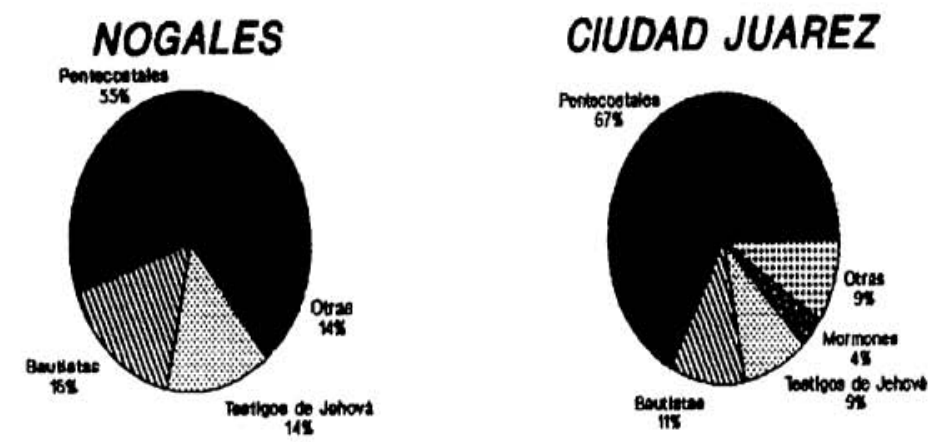

NUEVO LAREDO

\section{MATAMOROS}
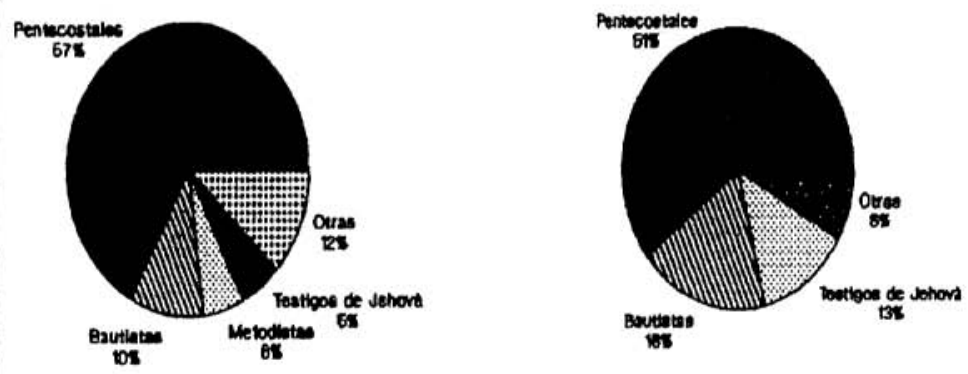

Figura 2. Campo protestante de la frontera norte por entidad según corrientes principales, 1988.

FUENTE: Alberto Hernández (1988). 


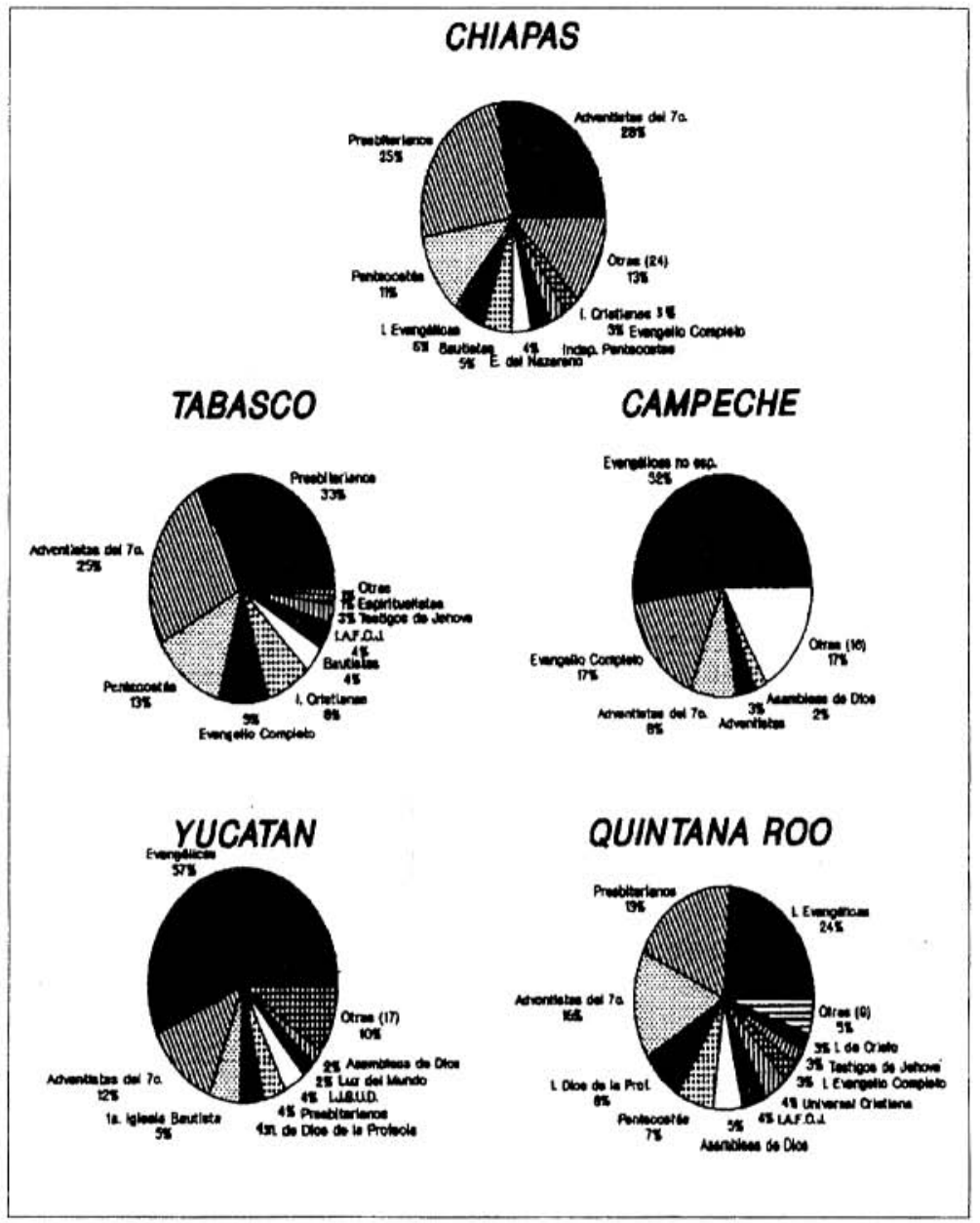

Figura 3. Campo protestante del sureste por entidad según denominaciones principales, 1987.

FUENTE: Gilberto Giménez (1987). 
Los datos sociograficos aportados por las encuestas complementan esta vision. Analizando las fechas de aparición de las congregaciones por municipio (figuras 4 y 5), pueden observarse dos momentos de aceleración en ambos casos, aunque con distinta intensidad: general a partir de 1950, y de manera particular los casos de Ciudad Juárez, Tijuana, Mexicali y Cárdenas en 1970. La mayor parte de las congregaciones encuestadas -arriba de $69 \%$ en 9 casos de 11-, aparecieron en las dos últimas décadas, ${ }^{9}$ siendo las excepciones Mexicali, que para 1970 tenía ya más del $40 \%$ de las congregaciones actuales, y Comalcalco que tenía el $37 \%$.

Hay otro rasgo que llama la atencion: las nuevas congregaciones por década en la frontera norte - salvo el caso de Tecate- superaron las 50 unidades en 1980 y las 100 en 1990 (llegando a 238 en Ciudad Juárez y 182 en Tijuana), mientras que entre los tabasqueños sólo Cárdenas saltó de 52 a 186 en ese mismo periodo, y el resto vio aparecer contingentes de 36,21 y aun menores. Si hemos visto que en términos relativos el peso del protestantismo es considerablemente mayor en los municipios del sureste, y que en términos absolutos la diferencias no son muy grandes, ¿ cómo se explica esta aparente contradicción, en la cual los municipios norteños parecen tener mayor dinamismo de crecimiento?

La respuesta tiene que ver con la composición de los campos respectivos, con su mayor proclividad a la homogeneización o a la diversificación, pues cabe recordar que el número de congregaciones es sólo un indicador del crecimiento de los grupos protestantes pero no el único ni el mejor. Como señalara Valderrey (1985), el crecimiento de la disidencia religiosa tiene que ver no sólo con la aparición de nuevos grupos, sino con el crecimiento y consolidación de algunos de los ya existentes, en particular fuerzas emergentes de fines del siglo pasado y principios del actual, como, por ejemplo, la Iglesia Apostólica de la Fe en Cristo Jesús o la Iglesia Adventista del Séptimo Día, fuerzas intermedias que han ganado espacio y mantienen una creciente presencia en el mercado de bienes simbólicoreligiosos.

9 En esto hay un sesgo evidente. Dado el carácter relativamente transitorio y fugaz de muchos grupos que conforman este segmento del campo religioso, la probabilidad de las congregaciones de ser detectadas varía en relación inversa con la distancia de su año de aparición; esto es, cuanto más tiempo tenga de haber sido fundada, mayor es la probabilidad de desaparición y, por lo tanto, menor la de su detección. Esto contribuye a "inflar" los porcentajes de los periodos recientes.

Por otra parte, sin embargo, la presencia actual de congregaciones fundadas hace un siglo y hace 50 años, es un indicador claro de su consistencia, y por tanto de su importancia como tradiciones religiosas dentro del campo. 


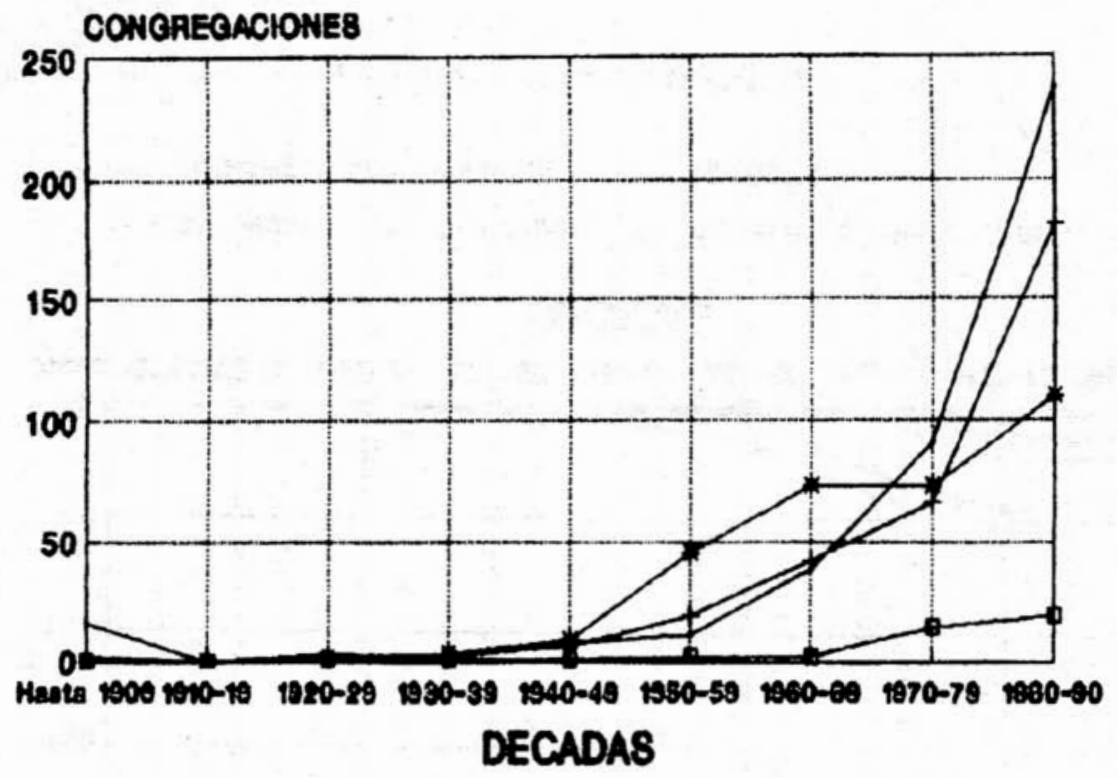

- co. Juarez + thuana * mexicall $\rightarrow$ tecate

Figura 4. Número de congregaciones aparecidas por década 1887-1990.

FUENTE: Inventario de organizaciones religiosas en las ciudades de Tijuana, Ciudad Juárez y Matamoros, julio-agosto, 1987, Colef; Molina, et. al. (1988); Molina (1990). 

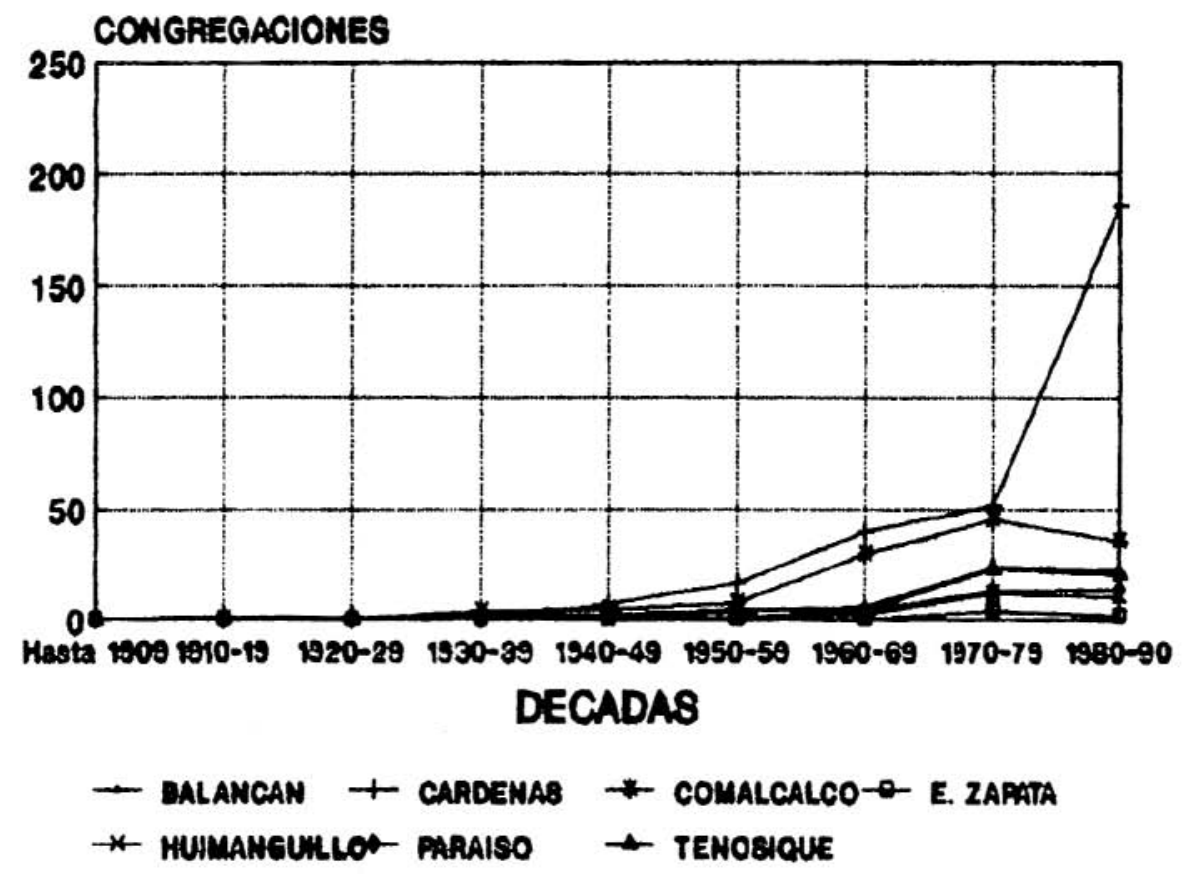

Figura 5. Número de congregaciones aparecidas por década 1887-1990. FUENTE: Valderrey (1988). 
Así, este rasgo de las entidades norteñas sugiere no una mayor dinámica de crecimiento, sino una mayor diversificación de su campo religioso.

\section{RASGOS ESPECÍFICOS DE LOS SUBCAMPOS RELIGIOSOS}

Considerados en conjunto los cuatro municipios de la frontera norte (figura 6), la composición revela un grado muy alto de diversificación, con los Testigos de Jehová (TJ) como la denominación principal (16\%), seguidos por diversas organizaciones pentecostales: Pentecostés, ${ }^{10}$ Iglesia Apostólica de la Fe en Cristo Jesús (IAFCJ), Asambleas de Dios, Bautista (de rito pentecostal), Cristiana y Evangelista; si le aplicamos la tipología de Meneses considerando el número de congregaciones como criterio, podemos ver un campo extremadamente plural, en el cual hacen falta seis organizaciones distintas para alcanzar el $50 \%$, y el rubro "otras", que comprende $44 \%$, está integrado por más de 100 denominaciones distintas.

En contraste, el conjunto del sureste se presenta como un campo bifurcado (figura 7), con la Iglesia Evangélica Nacional Presbiteriana (IENP) como la fuerza mayoritaria (35\%), duplicando el porcentaje de la segunda denominación, la Iglesia Adventista del Septimo Día. (IASD); entre ambos agrupan a más del $50 \%$ de las congregaciones, y junto con la Iglesia de Dios del Evangelio Completo (IDEC), abarcan casi dos terceras partes. La proporción de testigos de Jehová (1.2\%), incluida entre las denominaciones mayores, permite visualizar su escasa presencia en el conjunto. Nótese, a la vez, cómo la Iglesia Apostólica de la Fe en Cristo Jesús y las Asambleas de Dios (AS) aparecen como fuerzas medias.

$\mathrm{El}$ análisis de la evolución histórica de las principales denominaciones también arroja resultados interesantes (figura 8). En la frontera norte se observa que hasta 1960 había un predominio pentecostal, encabezado por la IAFCJ, que alcanzó su tope en los cincuenta (17 nuevas unidades) y después ha decrecido en su dinámica de creación de nuevas congregaciones: 13,8 y 4 , respectivamente; las congregaciones Pentecostés y las Asambleas de Dios las rebasan en 1980, y las dejan muy atrás en la década siguiente, cuando pasan de 11 a 35 y 43 . Un rasgo adicional en el ámbito protestante: de sus tres vertientes principales, la más dinámica es la más nueva y menos formalizada (Pentecostés), mientras que una de las tradicionales (LAFCJ) mantiene su presencia pero no su ritmo expansivo, y la otra (Asambleas de Dios) parece ajustarse a las nuevas condiciones.

${ }^{10}$ Que, como la designación de cristiana, evangelista o pentecostal, refieren no una denominación propiamente dicha, sino grupos identificados entre sí doctrinalmente, pero no adscritos formalmente a una misma organización, como es el caso de la LAFCJ o ciencia cristiana, por ejemplo, que sí son identificables como organizaciones individuales. 


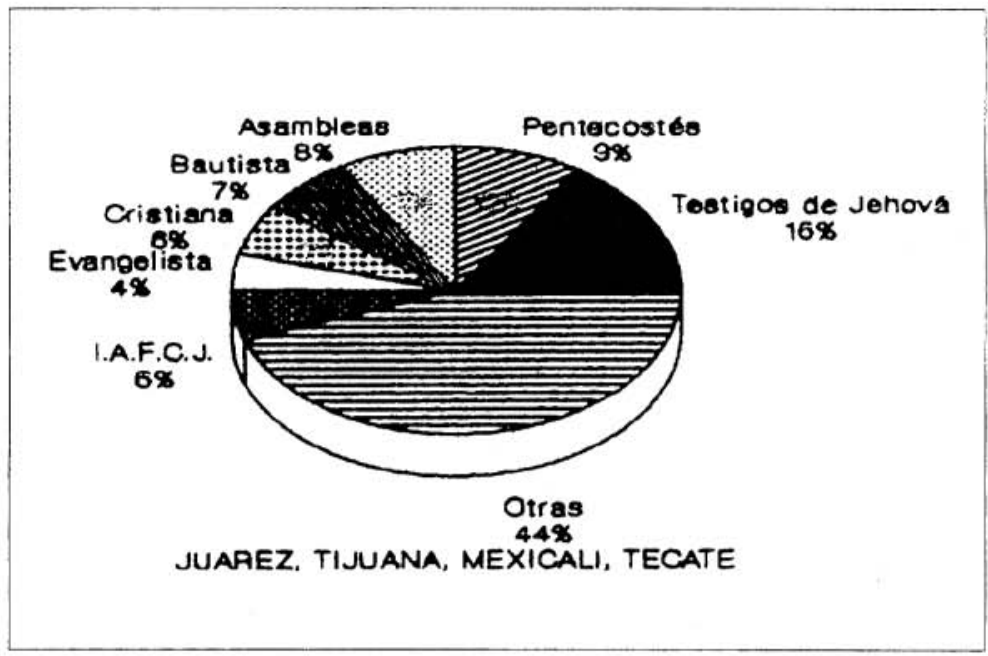

Figura 6. Principales denominaciones en cuatro municipios de la frontera norte.

FUENTE: Hernández (1997); Molina (1990).

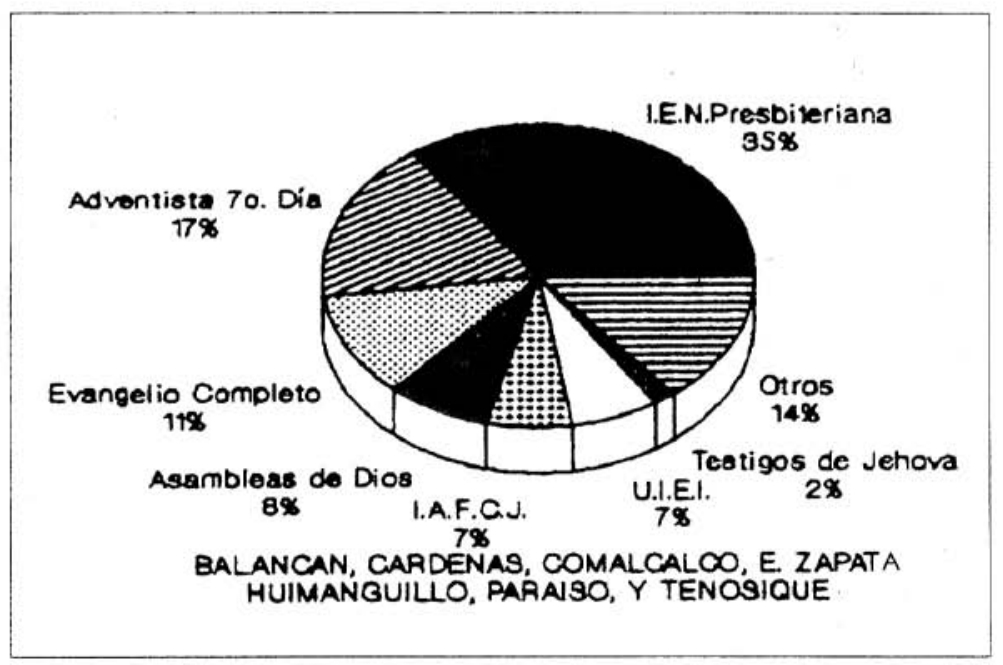

Figura 7. Principales denominaciones en siete municipios de Tabasco.

FUENTE: Valderrey (1988). 
Sin embargo, pese a que esto implica triplicar y cuadruplicar su número en cada caso, el mayor crecimiento lo registran los testigos de Jehová que pasan de 9 nuevas unidades en 1970, a 45 en 1980, y a 75 en 1990, convirtiéndose en la denominación principal de la región, aun cuando ocupe apenas una sexta parte del campo posible: un campo además, que presenta variaciones significativas en su composición de una década a otra.

Algo distinto es lo que ocurre en el caso del subconjunto tabasqueño (figura 9). Por principio, la composición tiende a mantenerse estable, salvo leves variantes registradas en las dos últimas décadas; pero además, la variación de la estructura tiene dos patrones diferenciados: la de las fuerzas principales (presbiterianos y adventistas), que alcanzan su tope en los setenta y descienden en el periodo siguiente, y la de dos fuerzas emergentes, la Iglesia de Dios del Evangelio Completo, relativamente nueva, y las Asambleas de Dios, de añeja presencia, ambas pentecostales típicas. Una interpretación inicial es que la dinámica diferente de estos dos pares tiende a transformar un campo religioso fuertemente concentrado en dos agrupaciones, a uno con mayor equilibrio entre por lo menos cuatro fuerzas.

Instalados ya en el análisis por denominaciones, podemos descender al nivel de agregación para analizar la composición por municipios. En la figura 10 se incorporan dos municipios más y dos fuentes de información (lo cual explica las diferencias en los casos de Ciudad Juárez y Tijuana, con respecto a la composición basada en la información de Alberto Hernández). La figura 10, construida a partir del número de congregaciones de cada denominación, revela los rasgos principales de cada ciudad: son, sin excepción, campos pluralistas que requieren del concurso de más de seis organizaciones distintas para aglutinar $50 \%$ de la feligresía total. Por otra parte, en los cuatro municipios de Baja California, los testigos de Jehová son el grupo con más congregaciones, circundado por la LAFCJ, las Asambleas de Dios, los adventistas, los mormones, y la Convención Nacional Bautista, entre otras. En Ciudad Juárez y Matamoros, los testigos de Jehová ocupan el tercero y segundo lugar. En estas regiones, la influencia bautista proviene con mucha fuerza del campo religioso del sur de Estados Unidos, en particular Texas. Hay fuerzas regionales y locales, ${ }^{11}$ como la Clínica de Almas Jesús Salva, notable sólo en Mexicali, o la Iglesia Bautista Bíblica Fundamental, restringida al área rural de Mexicali. ${ }^{12}$

\footnotetext{
${ }^{11}$ Un análisis comparativo entre municipios de la frontera norte puede ser visto en Alberto Hernández, 1996.

12 En este caso, es necesario actuar con cautela para no confundir organizaciones unívocamente definidas que se desarrollan en un campo, con aglomerados insuficientemente clasificados, que pueden aparecer como organizaciones, siendo sólo construcciones del propio investigador.
} 


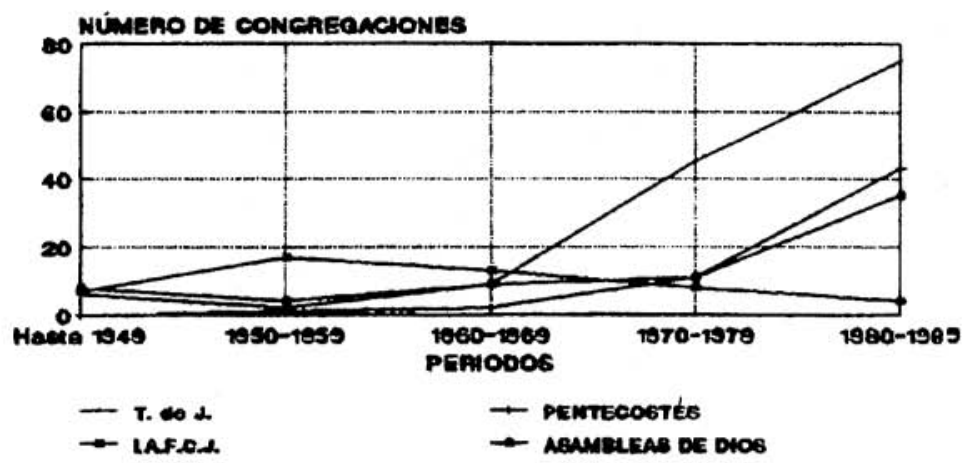

Figura 8. Evolución de las principales denominaciones en la frontera norte 1900-1990.

FUENTE: Hernández (1997); Molina (1989 y 1990).

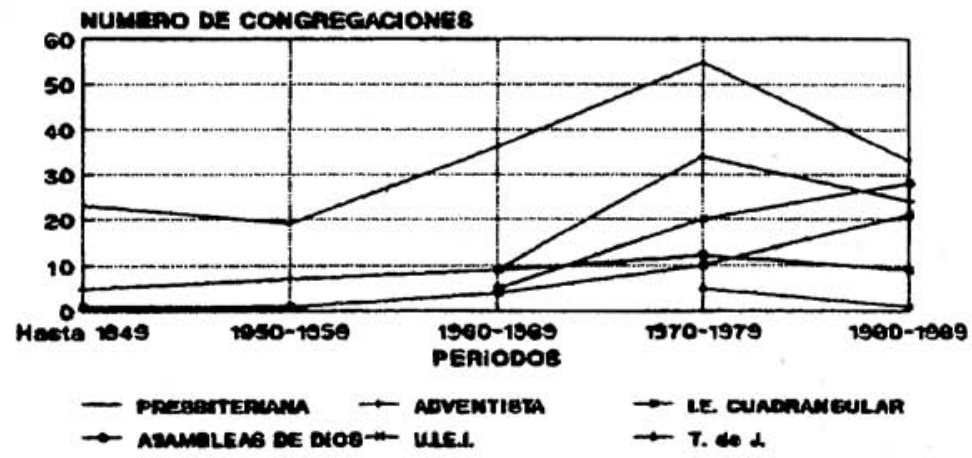

Figura 9. Evolución de las principales denominaciones en siete municipios de Tabasco 1887-1988.

FUENTE: Valderrey (1988). 
Otro acercamiento posible lo logramos a través del número de asistentes a los servicios religiosos por cada denominación (figura 11). ${ }^{13} \mathrm{Los}$ patrones mencionados arriba se confirman en este caso, tales como la extrema pluralidad y el predominio claro de los testigos de Jehová, así como la presencia de sus principales alternantes, los multicitados LAFCJ y Asambleas de Dios, y las organizaciones paraprotestantes de los adventistas y los mormones.

Si se compara esta composición con la anterior basada en el número de congregaciones, es posible observar cómo el predominio de los testigos de Jehová se acentúa alcanzando un promedio general de $17.5 \%$, lo que sugiere niveles de participación mayores a los del conjunto. Más adelante volveremos sobre los niveles de participación comparada.

El estudio detallado de los municipios de Tabasco (figura 12) confirma el patrón regional bifurcado, pero le incorpora importantes matices: son bifurcados cuatro de los seis campos, y en tanto que el de Huimanguillo es pluralista - con tres denominaciones - y el de Paraíso es homogéneo; empero, el de Comalcalco es semihomogéneo, ya que la primera fuerza concentra $47 \%$, y el de Huimanguillo está fuertemente orientado a la bifurcación (42\%); sólo el de Tenosique es casi simétricamente bifurcado.

A nivel denominacional, la IENP predomina claramente en Paraíso, Comalcalco y Cárdenas, y por poco margen en Tenosique, compartiendo esa posición con los adventistas en Huimanguillo, y siendo relegados al tercer lugar en Balancán. Los adventistas son primeros en Huimanguillo y Balancán, y segundos en el resto de los municipios; destacan además la LAFCJ y la IDEC.

En el caso del número de asistentes a los servicios religiosos (figura 13), se observan ciertas variaciones: siguen siendo bifurcados Cárdenas y Comalcalco (los dos mayores), pero también lo es Huimanguillo, el tercero en tamaño, mientras que Tenosique y Balancán aparecen como pluralistas, y el patrón homogéneo se radicaliza en Paraíso, donde la IENP comprende casi $70 \%$ del total de asistentes a los cultos.

${ }^{13}$ En estos casos se suelen usar tres indicadores: el número total de miembros, el de miembros bautizados, y el de asistentes a los servicios religiosos (o su equivalente). Los tres son respuestas de opinión; es decir, son calculadas grosso modo por el entrevistado más que consultadas directamente en archivos o estadísticas.

- El primer indicador varía en su cobertura porque a veces se incluye a los miembros pasivos (no participantes); en otras, a los participantes esporádicos, y en algunas se restringe a los más comprometidos con el grupo.

- El segundo tampoco permite mucha precisión debido a que lo que se entiende por "bautizado" significa cosas muy distintas para las diversas agrupaciones, siendo un caso notable el de los testigos de Jehová, que no incluyen como bautizados a la totalidad de los publicadores. 

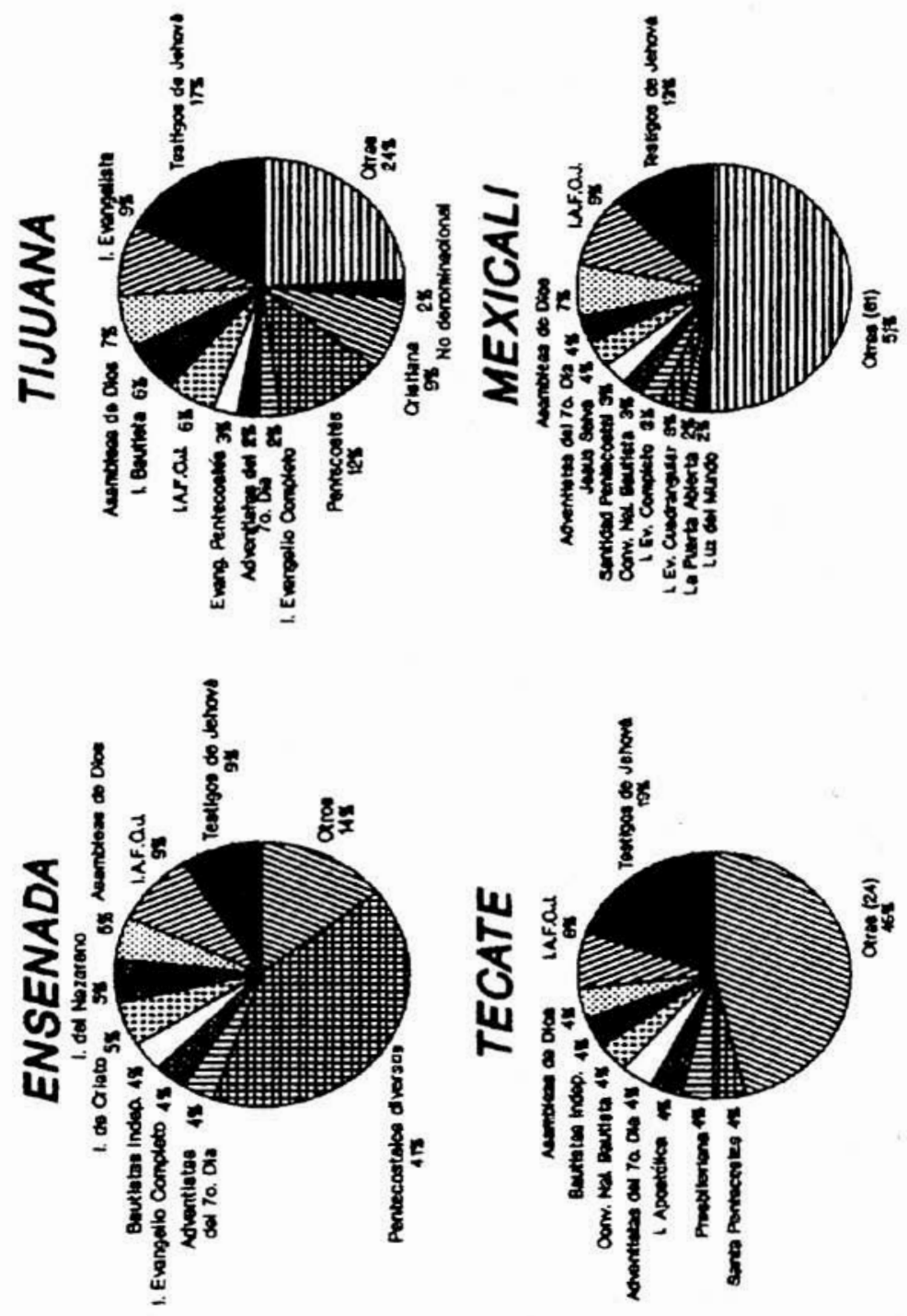


\section{CIUDAD JUAREZ}

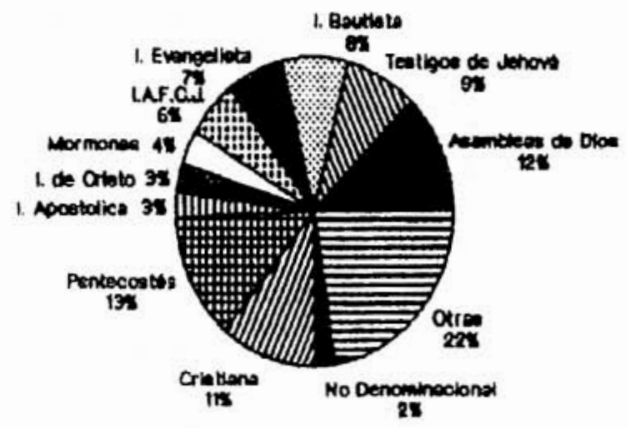

MATAMOROS

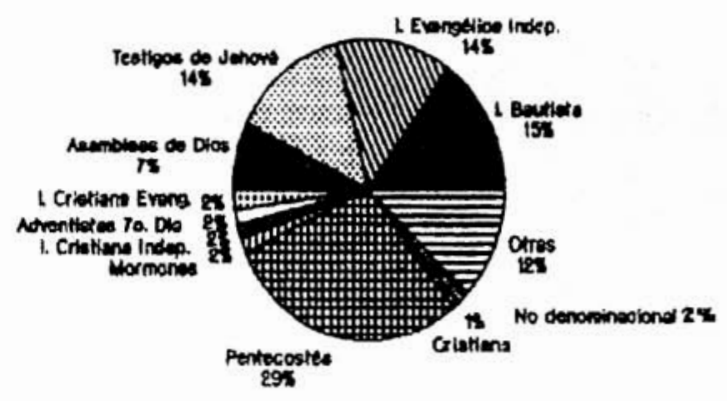

Figura 10. Campo protestante de la frontera norte por entidad según denominaciones principales, 1988. FUENTE: Rodolfo Casillas (1988); Eduardo Backoff (1989); José Luis Molina (1988). 


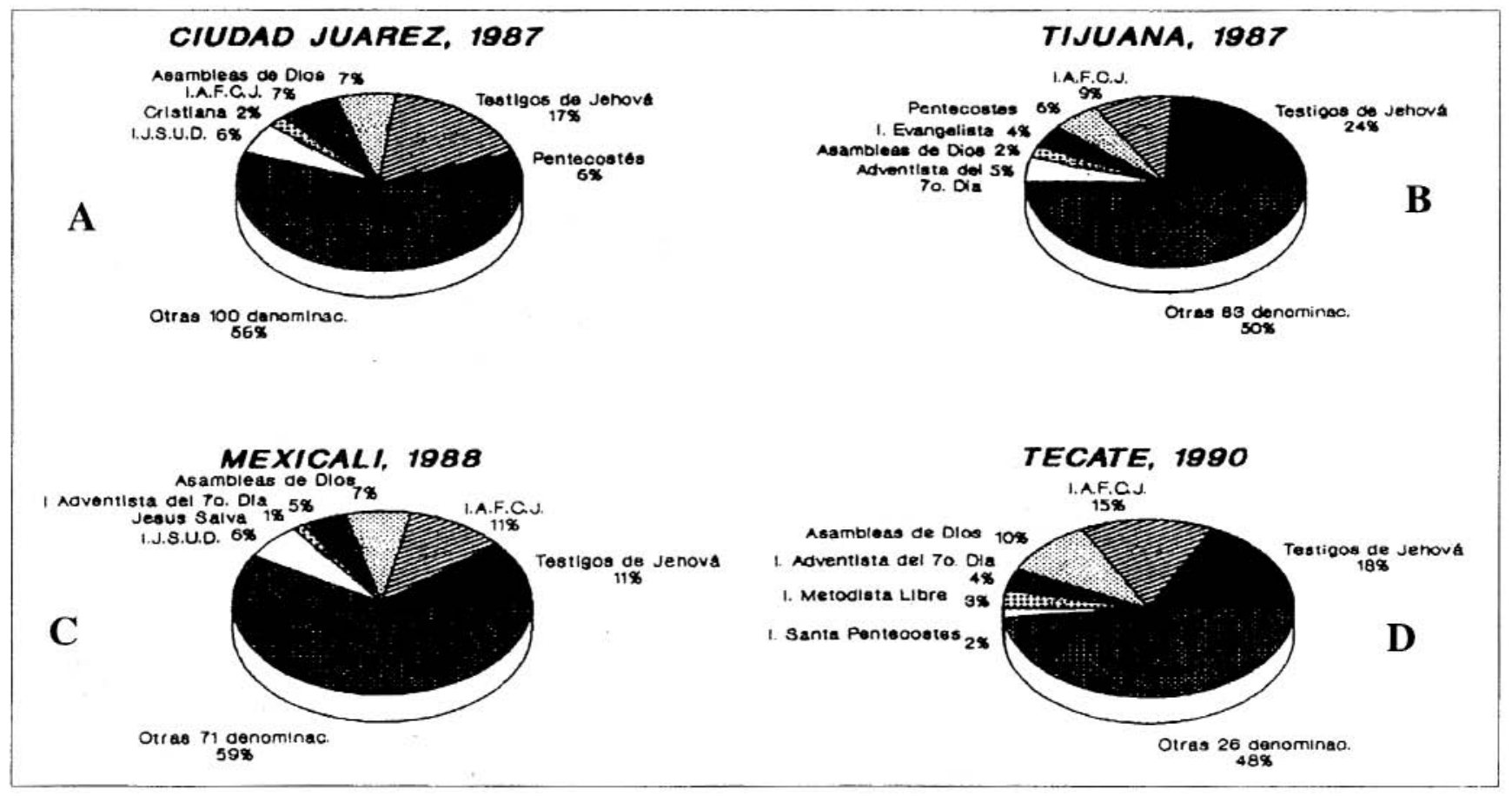

Figura 11. Denominaciones según número de asistentes a los cultos en cuatro municipios de la frontera norte. FUENTE: A y B) A. Hemández (1997); C y D) J.L. Molina (1989). 
Estos rasgos peculiares de cada segmento del campo religioso requieren de explicaciones de orden histórico (y microhistórico), político, cultural y organizacional que trascienden los límites de nuestro análisis. ${ }^{14}$ Pero queda ahí la constatación de estos campos que, siendo productos de la misma matriz, y pareciendo tan homogéneos desde un nivel de análisis general, terminan por aparecer como complejos y singulares, aunque inevitablemente emparentados.

\section{GRADOS DE DIVERSIFICACIÓN DE LOS CAMPOS RELIGIOSOS MUNICIPALES}

El análisis de la composición de los segmentos del campo religioso nos ha dado ya una idea del grado de concurrencia que tienen los mercados religiosos municipales, y nos muestra cómo cada segmento tiene una estructura y dinámica particular que requieren de estudios específicos.

Las tendencias hacia una mayor o menor diversificación en cada caso pueden ser determinadas de una manera más precisa que por la mera evaluación de su composición, elaborando un índice de diversificación (cuadro 2) que permita dar cuenta de la posición concreta de cada municipio en el espectro diversificación-especialización, ${ }^{15}$ así como correlacionar dicha posición con otras variables.

Lo primero que salta a la vista es la diferencia de índices entre los dos conjuntos, que demuestran, sin sombra de duda, que los municipios de la frontera norte están más diversificados, alcanzando índices superiores a 0.9 en casi todos los casos, en tanto que los de Tabasco registran valores entre 0.855 y 0.417 (en Paraíso, por supuesto), ${ }^{16}$ ubicándose alrededor del 0.7 como promedio.

14 Como la que ha emprendido Felipe Cuamea (1995:107-130) en el ensayo Religión y comportamiento político en México: En busca de tendencias regionales.

5 El índice está tomado del campo del análisis regional, y específicamente de María Eugenia Negrete (1984), quien a su vez lo retoma de Gibbs y Martín. Está calculado con la fórmula:

$$
I=1-\frac{\sum x^{2}}{\left(\sum x^{2}\right)}
$$

En donde $\mathrm{I}=$ índice de diversificación.

$\mathrm{x}=$ número de personas o miembros de cada una de las denominaciones religiosas (asistentes a los servicios religiosos o bautizados o total de miembros).

10 Por su pequeño volumen (apenas seis congregaciones) en el caso de Emiliano Zapata el indice es poco útil. 
BALANCAN
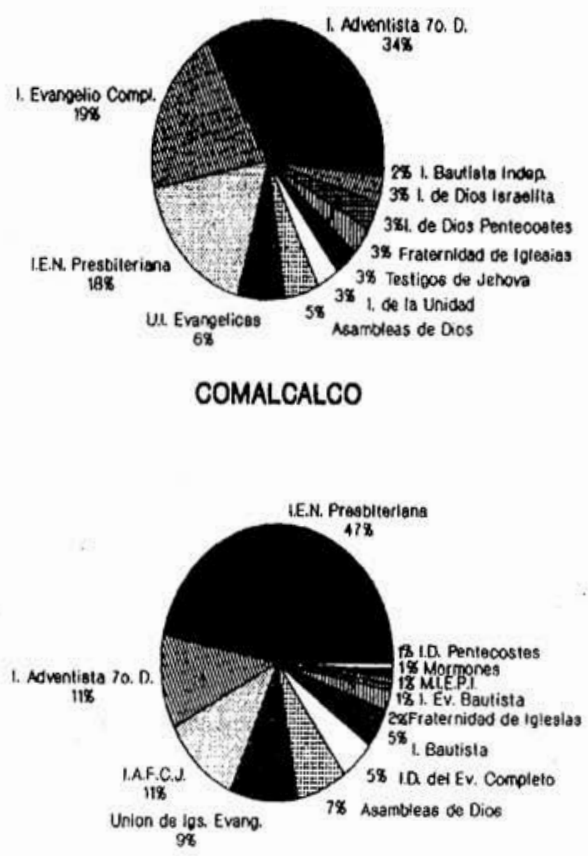

\section{CARDENAS}

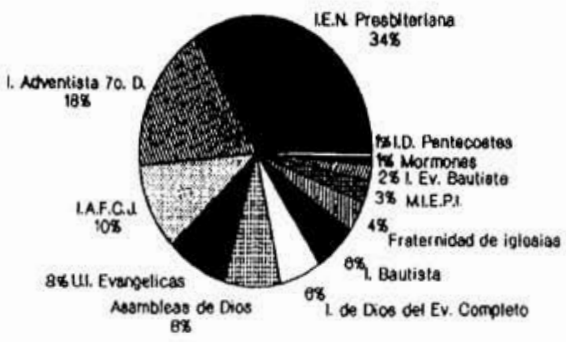

HUIMANGUILLO

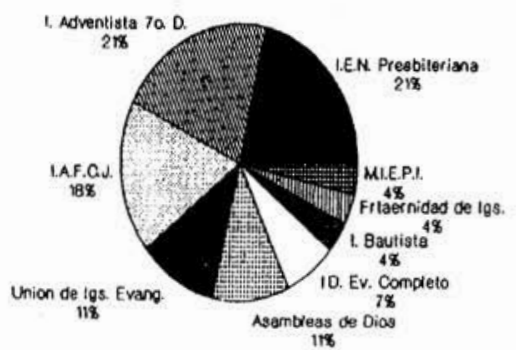


PARAISO

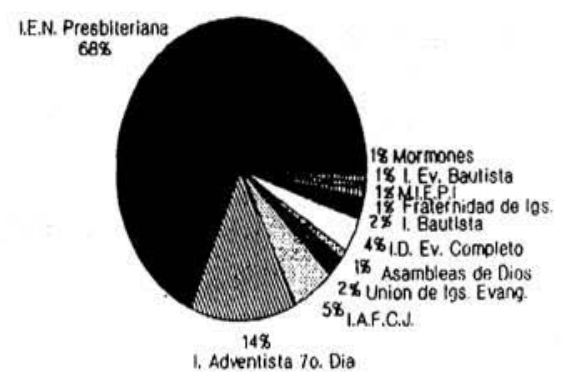

TENOSIQUE

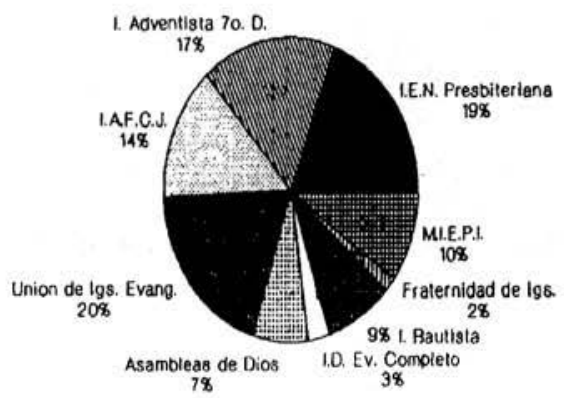

Figura 13. Denominaciones principales según número de asistentes a los servicios religiosos, en seis municipios de Tabasco, 1988.

FUENTE: Valderrey (1988). 
PARAISO

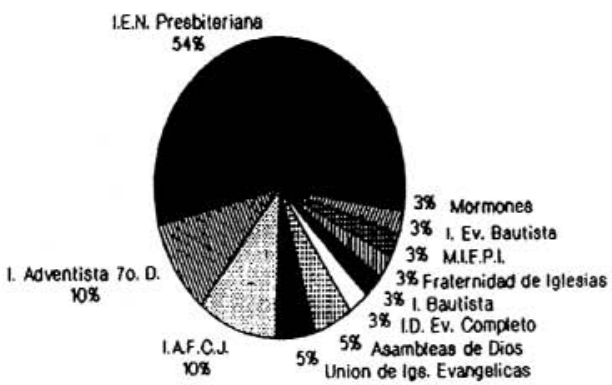

TENOSIQUE

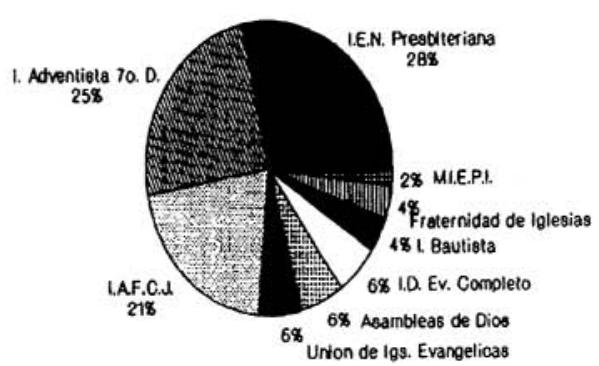

Figura 12. Denominaciones principales según número de congregaciones en seis municipios de Tabasco, 1988. FUENTE: Valderrey (1988). 


\section{BALANCAN}

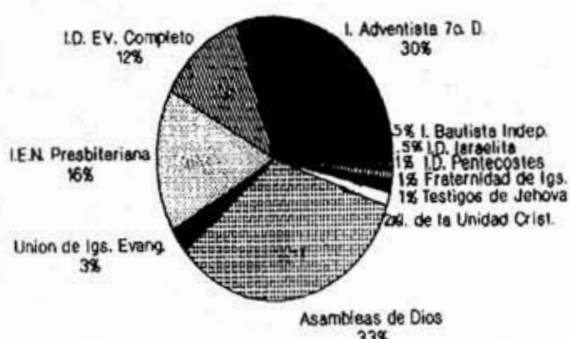

COMALCALCO

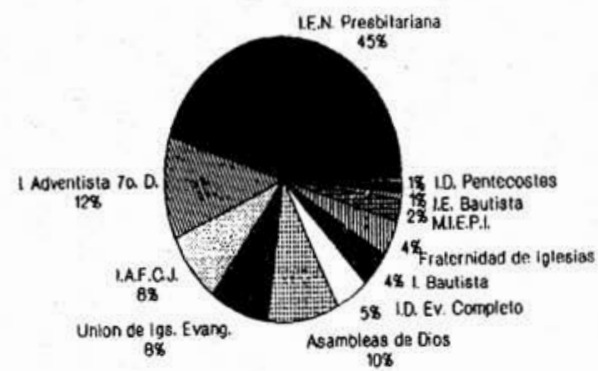

CARDENAS

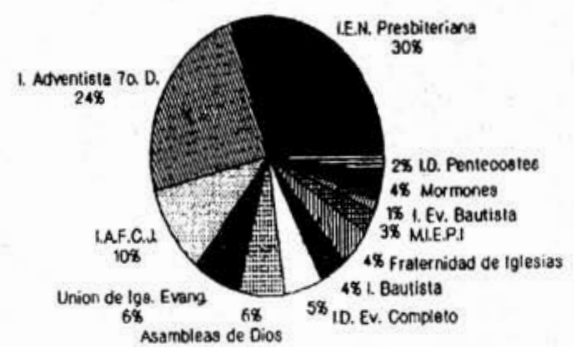

HUIMANGUILLOO

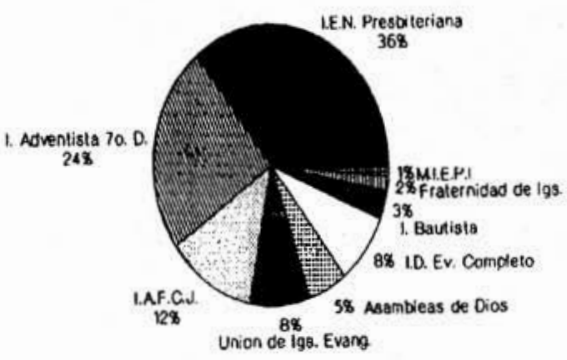


CUADRO 2. Índice de diversificación para municipios seleccionados.

$\begin{array}{lc}\text { Población } & \text { Índice de } \\ \text { total } 1990 & \text { diversificación }\end{array}$

Frontera norte

$\begin{array}{lrr}\text { Ciudad Juárez } & 680028 & 0.955 \\ \text { Tijuana } & 639451 & 0.953 \\ \text { Mexicali } & 518648 & 0.949 \\ \text { Tecate } & 44449 & 0.915 \\ \text { Promedio } & 470644 & 0.94\end{array}$

Tabasco

$\begin{array}{lrr}\text { Cárdenas } & 145943 & 0.814 \\ \text { Comalcalco } & 120319 & 0.743 \\ \text { Huimanguillo } & 112933 & 0.770 \\ \text { Paraíso } & 50500 & 0.417 \\ \text { Tenosique } & 41821 & 0.855 \\ \text { Balancán } & 40707 & 0.724 \\ \text { Emiliano Zapata } & 17174 & 1.000 \\ \text { Promedio } & 75628 & 0.76\end{array}$

FUENTE: Censos nacionales de población y vivienda, 1980 y 1990.

Estimaciones propias.

Por otra parte, es posible ver alguna relación con la jerarquía por tamaño, aunque no de manera lineal: en los cuatro municipios del norte se cumple, pero no en los del sureste, en donde el índice mayor le corresponde al más pequeño en tamaño, el segundo al quinto, y el menor al cuarto; además de ello, Tecate, menor que cuatro de los municipios tabasqueños, tiene un índice mayor que todos, con excepción de Emiliano Zapata (un caso que es poco relevante desde el punto de vista cuantitativo, con apenas seis congregaciones). En consecuencia, el coeficiente de correlación entre índice y tamaño del municipio para los 11 casos resulta muy bajo: 0.2 .

No obstante, es posible observar cómo, salvo los casos de Tenosique y Emiliano Zapata en el sureste y Tecate en el norte, los municipios con masas mayores tienen índices más altos. En el caso de Tecate puede hablarse de un efecto regional, dado que los mercados religiosos fronterizos se caracterizan por su pluralidad, al margen de su tamaño. 
En conclusión, podemos decir que hay indicios de la correlación entre el rango "tamaño de los municipios" y su "índice de diversificación", pero ésta no es unívoca y está además permeada por las configuraciones regionales características de cada segmento del mercado religioso. Arribamos así a la demostración analítica de algo que entendíamos por sentido común: que los campos religiosos de las zonas con mayor desarrollo urbano e industrial tienden a favorecer la conformación de campos mucho más segmentados, mientras que en las entidades más reducidas, tiende a reproducirse el viejo patrón de ocupación cuasi monopolica del espacio religioso, sólo que en la escala del subcampo protestante, y con la inevitable competencia que caracteriza al protestantismo.

\section{GRADOS DE PARTICIPACIÓN}

Siendo ésta una de las variables clásicas para el análisis de la religiosidad, no está exenta de dificultades: son pocos los grupos que llevan un registro puntual de la asistencia (testigos de Jehová y mormones se cuentan entre ellos); mide una masa fluctuante y por ello difícil de estimar; los grados de obligación varían de una denominación a otra, por lo cual, la participación tiene connotaciones distintas.

Con todo y esas limitaciones, la asistencia nos da una visión aproximada de la dinámica y potencial real de cada grupo, ya que nos indica no cuáles son los que se consideran miembros - donde puede haber muchos meramente formales-, ni tampoco los que conforman el núcleo (los bautizados), sino el total de los que hacen presencia en las reuniones.

En nuestro caso, vamos a analizar la relación entre la asistencia y el número de miembros bautizados, por un lado, y la asistencia y el total de miembros, por el otro; el primer indicador nos habla de la magnitud del grupo activo con respecto a su núcleo, mientras que el segundo nos indica qué porcentaje de esa hipotética feligresía está participando. Cuando el indicador es mayor que la unidad, entonces la asistencia rebasa al núcleo $o$ al total de miembros, y en esa medida nos habla de su dinamismo. En el cuadro 3 se incluyen sólo aquellos municipios en los cuales se tuvo un pleno control sobre las variables involucradas.

Analizado globalmente, es notoria la diferencia entre las dos regiones: si consideramos la relación número de asistentes/número de miembros bautizados, en la parte norteña $60 \%$ de los casos se ubican por encima de la unidad (es decir, que hay más asistentes a los servicios religiosos que miembros bautizados), mientras que en el sureste el porcentaje correspondiente es de $26 \%$. Lo mismo sucede en el caso de la relación número de asistentes/número total de miembros, en la cual $90 \%$ de los norteños supera 
el 0.5 , contra $32 \%$ de los tabasqueños. Los perfiles se revelan claramente diferenciados. A nivel de las denominaciones, destacan los testigos de Jehová en Mexicali, con clara diferencia sobre el resto, y las Asambleas de Dios ${ }^{17}$ y los testigos de Jehová en Tecate, alcanzando cifras sólo igualadas por la pequeña Unión de Iglesias Evangélicas Independientes, de Balancán; este último caso es el más notable de los municipios de Tabasco, seguido de los testigos de Jehová en Tenosique, las Asambleas de Dios en Paraíso, y la IENP en Balancán y Tenosique. Es notorio, además, cómo en los dos municipios mayores del bloque sureño - Cárdenas y Comalcalco- se registran los valores más bajos. Los datos indican que las denominaciones de la frontera norte presentan una dinámica de participación claramente superior, y que, en general, testigos de Jehová y Asambleas de Dios son las denominaciones más destacadas en este sentido.

Cabe aclarar que la LAFCJ es, en gran parte de los casos, la que tiene la mayor proporción de miembros bautizados con respecto a los otros dos rubros (aun en casos que no aparecen en la tabla), lo cual sugiere una tendencia a la estabilización de su número alrededor del núcleo, y con ello una menor dinámica de expansión; en otras palabras, la participación tiende a restringirse a los miembros plenamente comprometidos. Esto coincide con el análisis previo de la evolución histórica de cada denominación, que mostraba el decaimiento de la fuerza expansiva de este grupo, que fue el más notable en las primeras cinco décadas de este siglo.

\section{CONSIDERACIONES FINALES}

Mediante un conjunto diverso de fuentes de información y de procedimientos analíticos, hemos tratado de precisar el lugar que corresponde a las diferentes denominaciones dentro del campo religioso, y a la vez, hemos pretendido contribuir, aunque sea mínimamente, al conocimiento sociográfico del campo religioso nacional.

El análisis pone de manifiesto que el campo religioso de la frontera norte y el de Tabasco difieren, y que dentro de la heterogeneidad que caracteriza al subcampo no católico, en el norte, las tendencias a la diversificación son más intensas, mientras que en el sureste, la notable expansión de las últimas décadas parece orientada hacia una reproducción, relativa y a escala, del campo religioso general, con una fuerte propensión homogeneizante.

${ }^{17}$ El dato correspondiente a la relación número de asistentes/número total de miembros en el caso de las Asambleas de Dios parece algo errático con respecto al resto de la columna, por lo cual tiene que considerarse con reservas. 


\section{CUADRO 3. Índices de participación por denominación y municipio.}

\begin{tabular}{|c|c|c|c|c|c|}
\hline Denominaciones & $\begin{array}{l}\text { Asistencia } \\
\text { a los cultos }\end{array}$ & Bautizados & Total & $\begin{array}{l}\text { Asist./ } \\
\text { Bautiz. }\end{array}$ & $\begin{array}{l}\text { Asist./ } \\
\text { Total }\end{array}$ \\
\hline & & & & & \\
\hline \multicolumn{6}{|l|}{ Mexicali } \\
\hline Testigos de Jehová & 1743 & 897 & 1914 & 1.9 & 0.9 \\
\hline LAFCJ & 1672 & 1737 & 3025 & 1.0 & 0.6 \\
\hline Asambleas de Dios & 1089 & 1242 & 2191 & 0.9 & 0.5 \\
\hline Iglesia Adventista del 7o. Día & 748 & 658 & 1072 & 1.1 & 0.7 \\
\hline Total del municipio & 15622 & 13513 & 25978 & 1.2 & 0.6 \\
\hline \multicolumn{6}{|l|}{ Tecate } \\
\hline Testigos de Jehová & 578 & 265 & 560 & 2.2 & 1.0 \\
\hline LAFCJ & 474 & 517 & 650 & 0.9 & 0.7 \\
\hline Asambleas de Dios & 335 & 148 & 148 & 2.3 & 2.3 \\
\hline Iglesia Adventista del 7o. Día & 130 & 150 & 230 & 0.9 & 0.6 \\
\hline Total del municipio & 3239 & 2147 & 3510 & 1.5 & 0.9 \\
\hline \multicolumn{6}{|l|}{ Balancán } \\
\hline I. Adventista del 7o. Día & 729 & 861 & 1348 & 0.8 & 0.5 \\
\hline I. de Dios del Ev. Completo & 289 & 277 & 572 & 1.0 & 0.5 \\
\hline I. Ev. Nacional Presbiteriana & 395 & 323 & 572 & 1.2 & 0.7 \\
\hline Unión de Iglesias Ev. Indep. & 70 & 33 & 80 & 2.1 & 0.9 \\
\hline Total del municipio & 2427 & 1730 & 3032 & 1.4 & 0.8 \\
\hline \multicolumn{6}{|l|}{ Cárdenas } \\
\hline I. Ev. Nacional Presbiteriana & 1363 & 2441 & 4069 & 0.6 & 0.3 \\
\hline I. Adventista del 7o. Día & 1090 & 1444 & 2574 & 0.8 & 0.4 \\
\hline IAFCJ & 475 & 566 & 1008 & 0.8 & 0.5 \\
\hline Unión de Iglesias Ev. Indep. & 295 & 405 & 791 & 0.7 & 0.4 \\
\hline Total del municipio & 4680 & 6887 & 11925 & 0.7 & 0.4 \\
\hline \multicolumn{6}{|l|}{ Comalcalco } \\
\hline I. Ev. Nacional Presbiteriana & 1475 & 2367 & 4320 & 0.6 & 0.3 \\
\hline Asambleas de Dios & 385 & 563 & 1187 & 0.7 & 0.3 \\
\hline I. de Dios del Ev. Completo & 264 & 333 & 650 & 0.8 & 0.4 \\
\hline I. Adventista del 7o. Día & 268 & 411 & 595 & 0.7 & 0.5 \\
\hline Total del municipio & 3318 & 5041 & 9242 & 0.7 & 0.4 \\
\hline \multicolumn{6}{|l|}{ Emiliano Zapata } \\
\hline Unión de Iglesias Ev. Indep. & 85 & 82 & 200 & 1.0 & 0.4 \\
\hline I. de Dios del Ev. Completo & 70 & 78 & 125 & 0.9 & 0.6 \\
\hline I. Adventista del 7o. Día & 80 & 90 & 120 & 0.9 & 0.7 \\
\hline Total del municipio & 235 & 250 & 445 & 0.9 & 0.5 \\
\hline
\end{tabular}


CUADRO 3. (Continuación).

\begin{tabular}{lrrrrr}
\hline $\begin{array}{c}\text { TIT }=\begin{array}{c}\text { Asistencia } \\
\text { TIT }=\text { Denominaciones }\end{array} \\
\text { Asist./ }\end{array}$ & $\begin{array}{c}\text { Asist./ } \\
\text { a los cultosBautizados Total }\end{array}$ & Bautiz. & To \\
& & & & & \\
Huimanguillo & & & & & \\
I. Ev. Nacional Presbiteriana & 433 & 394 & 613 & 1.1 & 0.7 \\
IAFCI & 291 & 469 & 740 & 0.6 & 0.4 \\
I. Adventista del 7o. Día & 148 & 137 & 244 & 1.1 & 0.6 \\
Asambleas de Dios & 100 & 95 & 135 & 1.1 & 0.7 \\
Total del municipio & 1215 & 1358 & 2132 & 0.9 & 0.6 \\
Paraíso & & & & & \\
I. Ev. Nacional Presbiteriana & 910 & 1285 & 2698 & 0.7 & 0.3 \\
Asambleas de Dios & 185 & 141 & 388 & 1.3 & 0.5 \\
I. Adventista del 7o. Día & 72 & 72 & 117 & 1.0 & 0.6 \\
I. de Dios del Ev. Completo & 30 & 55 & 85 & 0.5 & 0.4 \\
Total del municipio & 1331 & 1732 & 3579 & 0.8 & 0.4 \\
Tenosique & & & & & \\
I. Ev. Nacional Presbiteriana & 192 & 161 & 352 & 1.2 & 0.5 \\
I. de Dios del Ev. Completo & 172 & 202 & 363 & 0.9 & 0.5 \\
I. Adventista del 7o. Día & 143 & 193 & 328 & 0.7 & 0.4 \\
Testigos de Jehován & 195 & 142 & 285 & 1.4 & 0.7 \\
Total del municipio & 1000 & 1108 & 1989 & 0.9 & 0.5 \\
\hline
\end{tabular}

En términos generales, estos datos encuentran una correspondencia teórica con el planteamiento de que la religiosidad de las regiones de mayores niveles de desarrollo urbano, difiere sustancialmente de la típica de aquéllas que tienen niveles inferiores y que están más próximas de la cultura rural (Molina, 1996).

En este marco general, los testigos de Jehová parecen mucho mejor adaptados a mercados de bienes simbólicos con un alto número de competidores, que aquéllos con tendencias monopólicas u oligopolicas, donde la oferta está fuertemente concentrada. Los pentecostales, considerados en conjunto, son mayoría en todas partes, pero vistos en sus organizaciones específicas (IAFCJ, Asambleas de Dios, La Puerta y muchas más), usualmente se ubican detrás de los testigos de Jehová en la frontera norte; en el sureste son mayoría absoluta, si bien enfrentan una fuerte competencia de los adventistas del Séptimo Día en algunos municipios. 
Baja California, estado al que corresponden la mayor parte de los datos manejados en el análisis para el caso de la frontera norte, presenta altos niveles de pluralidad y un escenario altamente propicio para este grupo religioso. Los datos son claros en ese sentido, y nos muestran que a principios de la presente década, los testigos de Jehová se habían convertido ya en la principal denominación religiosa de la frontera norte y del estado en cuanto a número de miembros y dinámica de crecimiento.

La limitación de la muestra analizada no nos permite aventurar mayores generalizaciones, pero sí nos ofrece una base relativamente clara para aproximarnos a la naturaleza del campo religioso global, y de cada una de las denominaciones dentro de él. Un paso más allá está la correlación con formas de comportamiento social y de identidades culturales e históricas en cada caso.

\section{BIBLIOGRAFÍA}

BACKHOFF, Eduardo E. 1987. "Templos religiosos en Ensenada, B.C.; un estudio cuantitativo", documento fotocopiado.

BASTIAN, Jean Pierre. 1986. "Protestantismo popular y política en Guatemala y Nicaragua", en: Revista mexicana de sociología, núm.3, julio-septiembre, México, Instituto de Investigaciones Sociales, UNAM.

CASILLAS, Rodolfo. 1988. "Emergencia protestante y disidencia religiosa en Chiapas", en: Estudios fronterizos, núm. 17, vol. vII, Año VI, septiembre-diciembre.

- 1989. "Una nueva aurora para las utopías religiosas: líneas de análisis de sus contenidos sociales", en: Frontera norte, vol. I, núm. 1, enero-junio de 1989, Tijuana.

CASILLAS, Rodolfo y Alberto Hernández. 1990. "Demografía y religión en México: una relación poco explorada", en: Síntesis, núm. 10, Paraguay.

CLARK, Víctor. 1986. "Los grupos religiosos en Tijuana", en: Inventario, núm. 28,11 de mayo, Tijuana, B.C.

- 1989a. “Grupos religiosos en Tijuana”, en: Enlace. UABC, núm. 18, abril-junio de 1989, Mexicali.

- 1989b. "Organizaciones religiosas y organizaciones privadas de beneficencia en la frontera norte (Tijuana): un primer acercamiento", documento fotocopiado, Tijuana, 1989. 
CUAMEA, Felipe. 1995. "Religión y comportamiento político en México: En busca de tendencias regionales", Revista mexicana de sociología, marzo.

DE LA ROSA, Martín. 1989. El impacto social del protestantismo. Mexicali, Universidad Autónoma de Baja California.

GIMÉNEZ, Gilberto. 1988. Sectas religiosas en el sureste: aspectos sociográficos y estadísticos, Cuadernos de la Casa Chata, núm. 161, México, Centro de Investigaciones y Estudios Superiores de Antropología Social (CIESAS) del Sureste.

GUILLÉN L., Tonatiuh y Alberto Hernández H. 1987. "Grupos religiosos protestantes en la frontera norte", reporte de investigación. El Colegio de la Frontera Norte, Tijuana, octubre de 1987.

HERNÁNDEZ, Alberto. 1989. "Sociogeografía de acción de las sociedades religiosas protestantes y paracristianas en cinco ciudades fronterizas", ponencia presentada en el V Encuentro Nacional: Estado, Iglesia y Grupos Laicos, en Guadalajara, Jalisco, 6-11 de noviembre de 1989.

- 1989. "Documento preparado para el Sr. Obispo Emilio Carlos Berlié Belaunzarán sobre los grupos religiosos protestantes en Tijuana", (documento fotocopiado). Tijuana, El Colegio de la Frontera Norte.

MASFERRER, Elio. 1991. "Nuevos movimientos y tendencias religiosas en América Latina”, en: Religiones latinoamericanas, enero-junio 1991, México, p. 46.

MENESES, Albert J. 1977. Religion at the Polls, Philadelphia, The Westminster Press.

MOLINA Hernández, José Luis, Martha E. Gutiérrez y Carlos Vásquez Malo. 1989. Sociedades religiosas cristianas no católicas. Estudio descriptivo, Mexicali, 1988, tesis de licenciatura, Mexicali, Escuela de Ciencias Sociales y Políticas, UABC.

MOLINA Hernández, José Luis.1992. "La noción de campo religioso", en: Intríngulis, núm. 4, enero-abril de 1992. Mexicali, Universidad Pedagógica Nacional, Unidad 021.

- 1996. "Los marcos urbano-regionales del campo religioso en México", en: Frontera norte, núm. 15, vol. 8. enero-junio de 1996. Tijuana, B.C.

NEGRETE S., María Eugenia. 1984. "Diversificación económica y sistemas urbano-regionales en México: un estudio exploratorio", en: $E l$ desarrollo urbano en México. Problemas y perspectivas, UNAM, México. 
ROSSETTI, José P. 1979. Introducción a la economía. Enfoque latinoamericano. México, Editorial Harla.

VALDERREY Falagán, José. 1983. "Propuesta para una tipología del protestantismo en América Central", documento mimeografiado, México.

- 1985. Las sectas en Centroamérica, Pro Mundi Vita, Boletín 100, 1985/1.

- 1988. Las sociedades religiosas no católicas en el estado de Tabasco: Factores de expansión e impacto sociopolítico (documento fotocopiado). México, CECOPE, Instituto de Cultura de Tabasco. 